\title{
Thoracoscopic surgical resection of thoracic neurogenic tumors
}

\author{
Patrick P. Han, M.D., and Curtis A. Dickman, M.D. \\ Division of Neurological Surgery, Barrow Neurological Institute, St. Joseph's Hospital and Medical Center, \\ Phoenix, Arizona
}

Five patients who harbored large intrathoracic paraspinal neurogenic tumors were treated using thoracoscopic techniques to achieve gross-total tumor resection. All tumors were entirely intrathoracic except one that had an intraspinal extension, and all tumors were treated entirely thoracoscopically except for this one. Gross-total resection was achieved in all cases. The mean clinical follow-up period was 6.8 months. Postoperatively, one patient developed Horner's syndrome. The only other complication was transient intercostal neuralgia (two patients), which has resolved in both patient. No evidence of disease was demonstrated clinically or on follow-up imaging in any patient. Thoracoscopy is an excellent modality with which to treat these tumors, in part because it is associated with significantly less morbidity than open thoracotomy and costotransversectomy procedures. Endoscopic transthoracic approaches reduce the approach-related soft-tissue morbidity by preserving the normal tissues of the chest wall, avoiding rib retraction and muscle transection, reducing postoperative pain, and facilitating recovery. This technique has become the senior author's (C.A.D.'s) surgical approach of choice for the removal of intrathoracic benign paraspinal neurogenic tumors. It has also become the preferred method by which to perform thoracic sympathectomy and remove central, herniated thoracic discs.

Key Words * neurofibroma * schwannoma * thoracoscopy * paraspinal tumor * spinal surgery

Thoracoscopy is a transthoracic endoscopic approach that has become widely used in the clinical setting during the past decade. Since 1993, we have used this thoracoscopy in a variety of spinal procedures and pathological conditions: herniated thoracic discs, sympathectomy, vertebral biopsy sampling, tumor resection, debridement of infections, spinal deformities, fractures, corpectomy, and spinal fixation. Because it is associated with significantly less morbidity than other techniques, thoracoscopy has become preferred over open thoracotomy for many purposes. It is associated with reduced pulmonary morbidity, postoperative pain, hospital stays, and blood loss, as well as being associated with better cosmetic outcomes. In this report we detail our clinical experience with the use of thoracoscopy to aid resection of benign paraspinal thoracic neurogenic tumors in five patients. The indications, operative techniques, and clinical outcomes are reviewed.

\section{CLINICAL MATERIAL AND METHODS}

\section{Signs, Symptoms, and Diagnoses}

Between 1995 and 1999, five patients underwent thoracic neurogenic tumor resection in which thoracoscopic techniques were used (Table 1). Patient age ranged from 7 to 52 years. Presenting clinical symptoms were as follows: new-onset right-sided chest pain, dyspnea and cough, hoarseness, and pneumonia. In one case the lesion was an incidental finding on chest radiography performed for a preemployment physical examination. Three schwannomas were resected, one paraganglioma, and one ganglioneurofibroma. All tumors were entirely intrathoracic except one that had an intraspinal extension, and all tumors were treated entirely thoracoscopically 
except that one. In this patient, the tumor required an open two-level laminectomy to excise the intraspinal component after the intrathoracic tumor was removed by thoracoscopic means.

\section{TABLE 1}

SUMMARY OF CL NICAL CHARACTER ISTKS IN FIVE PATIENTS UNDERGONG THORACOSCOPIC SURGERV FOR NERVE SHEATH TUMORS

\begin{tabular}{|c|c|c|c|c|c|c|c|c|c|c|c|}
\hline $\begin{array}{l}\text { Case } \\
\text { No. }\end{array}$ & $\begin{array}{c}\text { Age }\left(y^{r} s\right] \\
\text { Sex }\end{array}$ & $\begin{array}{l}\text { Presenting } \\
\text { Symptorns }\end{array}$ & Diagnosis & Site & $\begin{array}{l}\text { Intra- } \\
\text { thoracic } \\
\text { Tumor } \\
\text { Length } \\
\text { [crn] }\end{array}$ & $\begin{array}{l}\text { Dumb- } \\
\text { bell } \\
\text { Tumort }\end{array}$ & $\begin{array}{l}\text { Description } \\
\text { of Tumor } \\
\text { Mass }\end{array}$ & $\begin{array}{c}\text { Op } \\
\text { Time } \\
\text { (hrs] }\end{array}$ & $\begin{array}{l}\text { No. of } \\
\text { Por- } \\
\text { tads }\end{array}$ & $\begin{array}{l}\mathrm{EBL} \\
\text { (ml) }\end{array}$ & $\begin{array}{c}\text { Hospilal } \\
\text { Stay } \\
\text { (days] }\end{array}$ \\
\hline 1 & $52, F$ & $\begin{array}{l}\text { dyspnea, pro- } \\
\text { ductive cough }\end{array}$ & schwannoma & $\begin{array}{l}\text { rt T-2 } \\
\text { foramen }\end{array}$ & 6 & no & $\begin{array}{l}\text { partially } \\
\text { cystic, soft }\end{array}$ & 4 & 3 & 200 & 2 \\
\hline 2 & $43, F$ & $\begin{array}{l}\text { cough, hoarse- } \\
\text { ness }\end{array}$ & schmennoma & $\begin{array}{l}\text { rt T-2 } \\
\text { foramen }\end{array}$ & 4.5 & no & solid, soft & 3 & 3 & 150 & 2 \\
\hline 3 & 28, M & $\begin{array}{l}\text { new-onset rt- } \\
\text { sided chest } \\
\text { pain }\end{array}$ & $\begin{array}{l}\text { ganglioneuro- } \\
\text { fi trom a }\end{array}$ & $\begin{array}{l}\text { rt T-5 } \\
\text { foramen }\end{array}$ & 5 & yes & solid, rubbery & $2 \ddagger$ & 3 & 50 & 3 \\
\hline 4 & 21, M & $\begin{array}{l}\text { incidental mass } \\
\text { on } x \text {-ray }\end{array}$ & paragangliom a & rt T-8 & 4 & no & solid, rubbery & 4 & 3 & 300 & 3 \\
\hline 5 & $7, \mathrm{~F}$ & pneum onia & schnannoma & $\mathrm{rt} \mathrm{T}-4$ & 7 & no & solid, firm & 4.5 & 3 & 100 & 6 \\
\hline \multicolumn{12}{|c|}{$\begin{array}{l}\text { EBL = estimated blood loss. } \\
\dagger \text { Intraspinal exdision of mass. } \\
\mp \text { An additional } 50 \text { minutes mas required to remove the intraspinalextradural com ponent of the dum bbell tumor by making a } 2 \text {-inch } \\
\text { indision to perform a limited laminectomy }\end{array}$} \\
\hline
\end{tabular}

\section{Operative Technique}

Thoracoscopic resection of intrathoracic neurogenic tumors begins by identifying and protecting the vascular and visceral structures adjacent to the tumor. If the tumor possesses a cystic component, a long needle can be inserted into it to decompress the lesion internally. The parietal pleura is incised, opened widely, and mobilized from the margins of the tumor. The vascular supply to the tumor is coagulated using bipolar cauterization.

If the lesion is located peripherally on the intercostal nerve and does not enter the neural foramen, the normal segments of the intercostal nerve are identified proximally and distally to the tumor by using subperiosteal dissection to mobilize the neurovascular bundle from the rib. The tumor capsule is separated from the surrounding normal tissues by performing sharp and blunt dissection. The intercostal nerve is sectioned proximally and distally, leaving stumps of normal nerve tissue attached to the tumor that can be used as handles to grasp and manipulate the tumor as it is mobilized circumferentially. The tumor may be resected en bloc as a single specimen. However, to remove a large tumor from the thorax via an endoscopic portal, the lesion may have to be sectioned into pieces or placed within an endoscopic specimen bag.

In the case of nerve sheath tumors that extend into the neural foramen, an approach must be used such that the following events are avoided: extensive manipulation of the tumor, traction on its foraminal component, and avulsion of the proximal thoracic nerve root, which could cause cerebrospinal fluid (CSF) leakage or spinal cord injury. The intrathoracic tumor is first detached from the distal segment of the intercostal nerve. The distal tumor is mobilized from normal tissues by performing sharp and blunt dissection, avoiding traction on the proximal tumor mass within the neural foramen. Once sufficiently mobilized and detached from normal tissues, the tumor is sectioned, detaching its main portion from the portion entering the neural foramen. The bulk of the tumor mass can then be removed in a piecemeal fashion.

The stalk of the proximal tumor that remains within the neural foramen is resected last. To resect the foraminal component of the tumor completely, the dura and nerve root sleeve must be exposed and identified so that a suture ligature or hemoclip can be placed at the proximal nerve root to prevent CSF leakage. The epidural space is best identified by removing the head of the rib and pedicle of the vertebra caudal to the involved foramen, an exposure identical to the technique used to identify the dura during a thoracoscopic discectomy. The dorsal edge of the vertebral body may also have to be removed by drilling to provide adequate access to the foramen. After the tumor 
size is reduced by applying bipolar cauterization to its sheath, access to the proximal portion of the lesion within the neural foramen can be gained. The shrunken tumor stalk and proximal nerve root can then be mobilized more easily to identify the epidural space.

Once the dura and normal proximal nerve root are identified, the root sleeve is ligated using an endoscopic suture ligature or a hemoclip. The nerve root is amputated distal to the ligature, and the distal root stump is removed with the remaining tumor attached. The resection bed is inspected to verify that the tumor has been totally resected. Hemostasis is completed with bipolar cauterization, and absorbable hemostatic agents are placed over the epidural veins. The dura is inspected, and a Valsalva maneuver is performed to exclude the presence of a CSF leak.

If CSF is found to leak from the root sleeve or the dura, the dura should be closed using an endoscopic ligature, endoscopic suturing, dural closure clips, or fibrin glue and a fascial patch graft. The negative pressure that exists within the thorax during normal respiration creates a pressure gradient that could perpetuate a CSF leak postoperatively. Therefore, if the dura has been opened intraoperatively, the surgeon should make a watertight dural closure, place a lumbar drain to divert CSF flow, and avoid placing the chest tube to negative pressure (suction). If a chest tube is needed after surgery to promote reinflation of the lung or to drain any fluid collecting within the chest, it should be used briefly, minimizing the amount of suction (that is, $5 \mathrm{~cm} \mathrm{H}_{2} \mathrm{O}$ ). Alternatively, the chest tube can be placed to water seal, using gravity drainage. If hemostasis is satisfactory, the chest tube can be removed in the operating room or in the recovery room after the lung has fully reinflated.

\section{ILLUSTRATIVE CASE}

\section{Case 1}

This 52-year-old woman, an opera singer, harbored a right upper thoracic paraspinal mass discovered on a chest radiograph that was obtained to evaluate upper respiratory tract symptoms (dyspnea and cough). The results of neurological and physical examinations were normal. Magnetic resonance imaging demonstrated a 6-cm-diameter, cystic-enhancing tumor that arose from a widened right T-2 neural foramen (Fig. 1). The tumor did not extend intradurally.

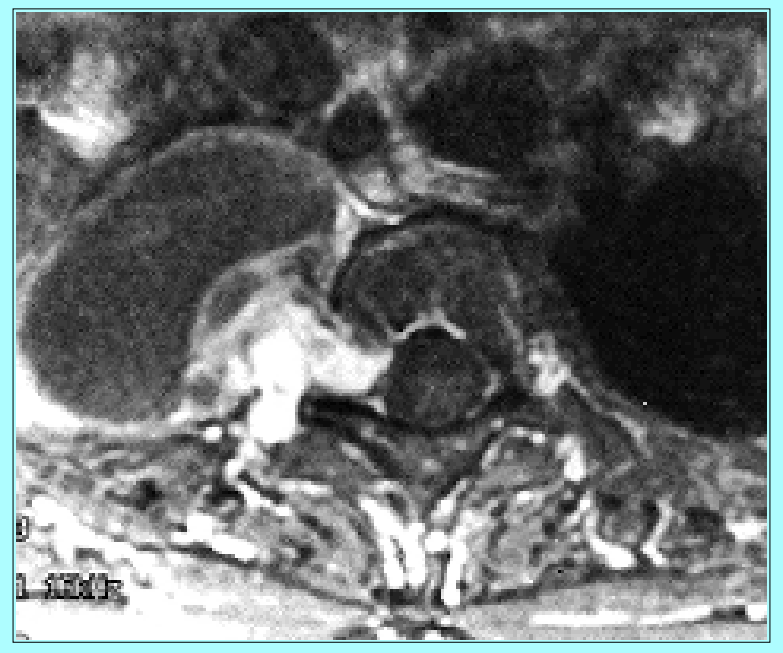

Fig. 1. Case 1. Gadolinium-enhanced axial magnetic resonance image revealing an enhancing tumor that has widened the neural foramen at T-2 and extended into the chest. A 6 X 6-cm spherical cyst extends into the chest, but the tumor does not extend intradurally. From Dickman CA, Apfelbaum RI: Thoracoscopic microsurgical excision of a thoracic schwannoma. Case report. J Neurosurg 88:898-902, 1998.

Surgery was performed using a right-sided thoracoscopic approach in which three flexible 15-mm-diameter portals were placed in the intercostal spaces to provide access for the endoscope and tools. Standard thoracoscopic microsurgical dissection techniques were used.[2] The tumor and adjacent vascular, visceral, and musculoskeletal structures were clearly identified (Fig. 2). 

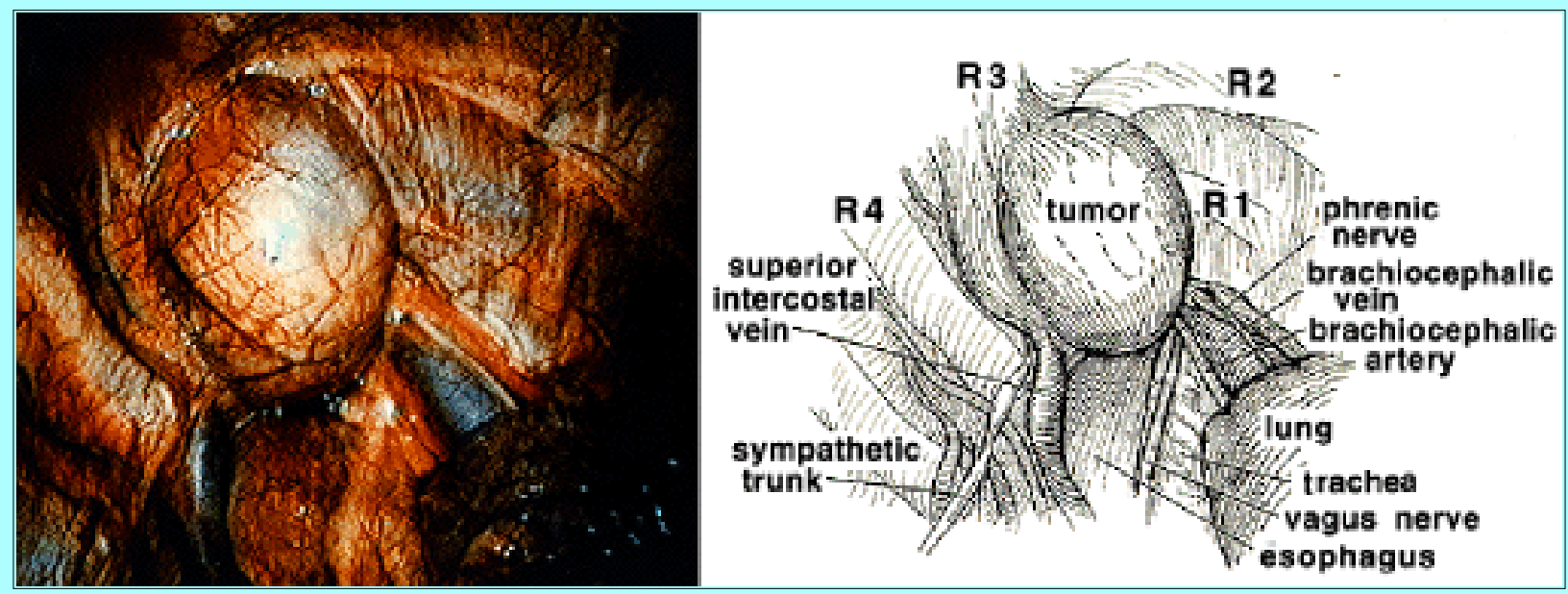

Fig. 2. Case 1. Intraoperative photograph (left) and corresponding illustration (right) showing an endoscopic view of the tumor and the anatomy of the thoracic cavity from a right-sided thoracoscopic approach. The large cystic tumor, which extends from the T-2 neural foramen into the apex of the chest, is adjacent to the spine, chest wall, trachea, esophagus, brachiocephalic and subclavian vessels, and the phrenic and vagus nerves. $\mathrm{R}=$ rib. From Dickman CA, Apfelbaum RI: Thoracoscopic microsurgical excision of a thoracic schwannoma. Case report. J Neurosurg 88:898-902, 1998.

First the cystic portion of the tumor was drained with a needle (Fig. 3 upper left and right), and then the tumor capsule was separated from the chest wall, adjacent vessels, and the mediastinum by performing sharp and blunt dissection in which endoscopic soft-tissue dissection tools were used (Fig. 3 center left and right). The thoracic component of the tumor was then mobilized and excised sharply in several large pieces. The rib head and pedicle were removed at $\mathrm{T}-3$ to expose the dura. The nerve root sleeve proximal to the tumor was ligated endoscopically (Fig. 3 lower left and right). A gross-total resection was thereby achieved. 


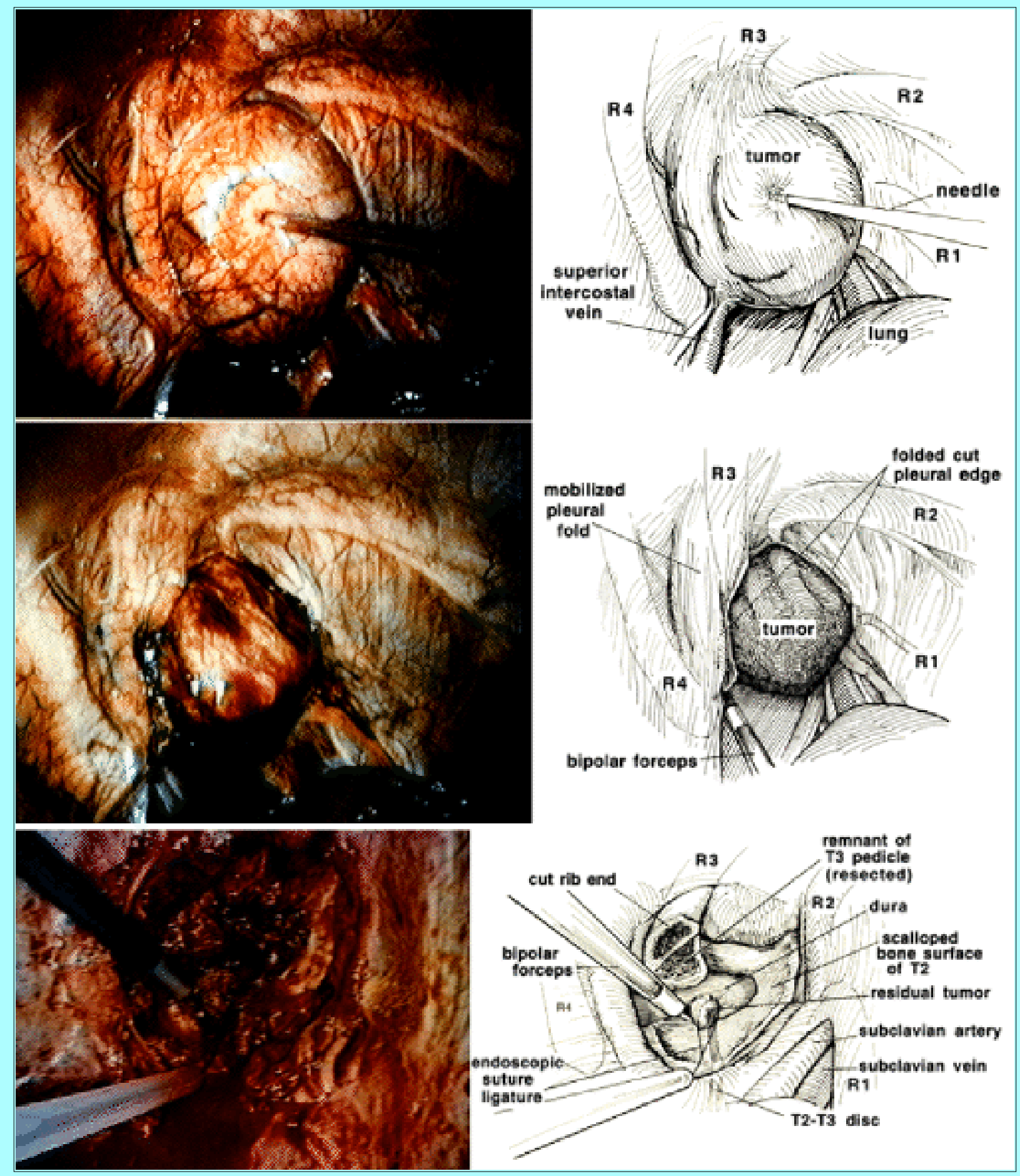

Fig. 3. Intraoperative photographs (left) and corresponding illustrations (right). Upper Left and Right: The tumor cyst is decompressed by inserting a long needle into it and withdrawing $30 \mathrm{ml}$ of xanthochromic fluid. Center Left and Right: The pleura is incised and dissected from the surface of the tumor to expose the tumor surface completely, which is then carefully separated from the adjacent vascular and visceral structures by using sharp and blunt dissection. Lower Left and Right: The tumor has been resected. The foraminal component of the tumor was resected after the dura and proximal T-2 root sleeve were exposed by removing the T-3 rib head and T-3 pedicle. Once the dura and proximal nerve root were identified, the proximal root was ligated using an endoscopic suture loop, and the root was divided distal to the ligature. The distal nerve root and the residual tumor were then removed completely by using sharp dissection. From Dickman CA, Apfelbaum RI: Thoracoscopic microsurgical excision of a thoracic schwannoma. Case report. J Neurosurg 88:898-902, 1998.

The patient was hospitalized for 2 days after surgery and experienced no postoperative complications. She resumed 
normal activity within 1 week of surgery.

\section{RESULTS}

Gross-total resection was achieved in all cases. The mean operative time was 3.5 hours (range 2-4.5 hours), and all procedures required three portals. The mean estimated blood loss was $160 \mathrm{ml}$ (range $50-300 \mathrm{ml}$ ); the mean length of hospital stay was 3.2 days (range 2-6 days), and the mean clinical follow-up period was 6.8 months (range 2-16 months). Postoperatively, one patient developed Horner's syndrome. Otherwise, only transient intercostal neuralgia, which eventually resolved, occurred at the portal sites in a few of the patients. Evidence of recurrent disease clinically or on follow-up magnetic resonance imaging was not demonstrated in any patient.

\section{DISCUSSION}

Various benign and malignant neurogenic tumors can arise from the spinal and paraspinal structures within the posterior mediastinum (Table 2). [3,8,9] Excision is required to diagnose the tissue definitively and to remove the tumor. Benign nerve sheath tumors are the most commonly occurring neoplasms (Table 3).[8,9] Schwannomas and neurofibromas are more often round, and more than $80 \%$ arise outside the spinal canal. They may grow within the segmental thoracic nerves, or they may arise from the phrenic or vagus nerves. The intercostal nerves can be sacrificed without consequences. If, however, tumor arises from the phrenic or vagus nerves, the nerves of origin should be preserved.

\begin{tabular}{|c|c|c|}
\hline \multicolumn{3}{|c|}{$\begin{array}{c}\text { TABLE } 2 \\
\text { DIFFERENTATION OF THORACK NEUROGEN K TUMORS }\end{array}$} \\
\hline Tum or Origin & Benign & Malignart \\
\hline ner've sheath & $\begin{array}{l}\text { schwannoma, neuro- } \\
\text { fitroma }\end{array}$ & $\begin{array}{l}\text { neurogenic schwannoma (malignant } \\
\text { schwannoma) }\end{array}$ \\
\hline autonomic ganglia & ganglioneuroma & ganglioneuro tlas toma, neuroblastoma \\
\hline $\begin{array}{l}\text { paraganglionic } \\
\text { system }\end{array}$ & $\begin{array}{l}\text { Paragangliom a (pheo- } \\
\text { chrom ocytoma \& } \\
\text { chemodectoma) }\end{array}$ & $\begin{array}{l}\text { malignant pheochromocytom a; malig- } \\
\text { nant paraganglioma. }\end{array}$ \\
\hline neuroectoderm & NÄ & primitive neuroectodermal tum or \\
\hline
\end{tabular}

\begin{tabular}{|c|c|}
\hline \multicolumn{2}{|c|}{$\begin{array}{c}\text { TABLE } 3 \\
\text { DISTRIBUTION OF } 202 \text { INTRATHORACIC } \\
\text { NEUROGEN K TUMORS }\end{array}$} \\
\hline Type & No. of Patients (\%) \\
\hline \multicolumn{2}{|l|}{ ner'e sheath tum or } \\
\hline schwannoma & $52(26)$ \\
\hline neurofitroma. & $21(10)$ \\
\hline neurogenic sarcoma & $2(1)$ \\
\hline \multicolumn{2}{|l|}{ autonomic ganglion tumor } \\
\hline ganglioneuroma & $50(25)$ \\
\hline ganglioneuro tlastoma & $28(14)$ \\
\hline neuroblastoma & 36 (18) \\
\hline paraganglioma & $7(3)$ \\
\hline peripheral neuroectodermal tum or & $6(3)$ \\
\hline
\end{tabular}

Compared with nerve sheath tumors, ganglionic tumors are usually elongated masses with tapered borders. Neurogenic tumors may become symptomatic, with the patient experiencing neurological symptoms, such as pain, erosion of the rib, vertebra, or pedicle; scoliosis; or foraminal enlargement. The most common tumors that become symptomatic with foraminal enlargement are schwannomas and neuroblastomas,[8] whereas those that most often become symptomatic with scoliosis are ganglioneuromas and ganglioneuroblastomas.[8] 


\section{Surgical Indications}

The most ideally suited tumors for transthoracic endoscopic resection are those located peripherally within the intercostal nerves or those that extend from the neural foramina into the chest cavity. Before the advent of thoracoscopy, these tumors required that a thoracotomy be performed for removal.[3,8,9] Resection of such nerve sheath tumors may be indicated to prevent spinal cord compression caused by the tumors growing into the spinal canal; to relieve mass effect within the chest when a large tumor has caused impaired pulmonary function; to prevent malignant transformation of a tumor; or to obtain a diagnosis of the tissue sample.[1,3-10]

In the thoracic spine, nerve sheath tumors in which a significant component of their mass within the spinal canal compresses the spinal cord (for example, classic dumbbell tumors) should not be approached solely endoscopically.[3] Intradural tumors are approached posteriorly or posterolaterally by performing a laminectomy, transpedicular approach, or costotransversectomy. The dura is opened to allow resection of the intracanalicular tumor and decompression of the spinal cord, and it is then closed in a watertight fashion. If the tumor also extends into the chest, a costotransversectomy approach can be used to resect small- to moderate-sized extensions of the tumor $(</=4 \mathrm{~cm})$. However, if a large component of a dumbbell tumor extends into the chest cavity, a thoracotomy or a thoracoscopic approach may be needed to obtain adequate visualization and access so that the intrathoracic component of the tumor can be resected safely. The risk of a CSF leak can be minimized by first resecting the foraminal and intradural tumor and then obtaining a watertight dural closure. Subsequently, thoracoscopy is performed to resect the residual tumor within the thorax.

Surgery is indicated for the definitive diagnosis and resection of these tumors. Only a few cases in which thoracoscopy was performed to excise intrathoracic neurogenic tumors have been reported.[5-7,10] However, thoracoscopy can be used successfully and as a preferred method to thoracotomy to resect thoracic neurogenic tumors.

\section{CONCLUSIONS}

The operative techniques used for the endoscopic resection of intrathoracic neurogenic tumors are straightforward, closely resembling the dissection techniques used to resect these tumors in open surgery. Gross-total resection was achieved in all our cases. Thoracoscopy provides an excellent alternative approach to these tumors because it is associated with significantly less morbidity than open thoracotomy and costotransversectomy. Endoscopic transthoracic approaches reduce the approach-related soft-tissue deficits by preserving the normal tissues of the chest wall, avoiding rib retraction, and reducing postoperative pain. These advantages translate into quicker recovery periods and return to normal activity. Currently, a laminectomy is best suited for treating intradural tumors that compress the spinal cord. Large dumbbell tumors that extend intradurally into the spinal canal and widely into the thorax can be treated with a staged, open posterior resection of the intradural and foraminal portions of the tumor and subsequently with an anterior thoracoscopic approach for the resection of the residual intrathoracic component.

\section{Acknowledgments}

Portions of the work presented here were adapted from Dickman CA, Apfelbaum RI: Thoracoscopic resection of intrathoracic neurogenic tumors, in Dickman CA, Rosenthal DJ, Perin N (eds): Thoracoscopic Spine Surgery. New York: Thieme, 1998.

\section{References}

1. Dickman CA, Apfelbaum RI: Thoracoscopic microsurgical excision of a thoracic schwannoma. Case report. J Neurosurg 88:898-902, 1998

2. Dickman CA, Apfelbaum RI: Thoracoscopic resection of intrathoracic neurogenic tumors, in Dickman CA, Rosenthal DJ, Perin NI (eds): Thoracoscopic Spine Surgery. New York: Thieme, 1998, pp 245-270 
3. Grillo HC, Ojemann RG, Scannell JG, et al: Combined approach to "dumbbell" intrathoracic and intraspinal neurogenic tumors. Ann Thorac Surg 36:402-407, 1983

4. Landreneau RJ, Dowling RD, Castillo WM, et al: Thoracoscopic resection of an anterior mediastinal tumor. Ann Thorac Surg 54:142-144, 1992

5. Landreneau RJ, Dowling RD, Ferson PF: Thoracoscopic resection of a posterior mediastinal neurogenic tumor. Chest 102:1288-1290, 1992

6. Lyons MK, Gharagozloo F: Video-assisted thoracoscopic resection of intercostal neurofibroma. Surg Neurol 43:542-545, 1995

7. McNulty PS, McAfee PC, Regan JJ: Biopsy of discs, vertebrae, and paraspinal masses, in Regan JJ, McAfee PC, Mack MJ (eds): Atlas of Endoscopic Spine. St. Louis: Quality Medical, 1995, pp 151-164

8. Reed JC, Hallet KK, Feigin DS: Neural tumors of the thorax: subject review from the AFIP. Radiology 126:9-17, 1978

9. Shields TW, Reynolds M: Neurogenic tumors of the thorax. Surg Clin North Am 68:645-668, 1988

10. Weder W, Schlumpf R, Schimmer R, et al: Thoracoscopic resection of benign schwannoma. Thorac Cardiovasc Surg 40:192-194, 1992

Manuscript received September 20, 1999.

Accepted in final form October 27, 1999.

Address reprint requests to: Curtis A. Dickman, M.D., Neuroscience Publications, Barrow Neurological Institute, 350 West Thomas Road, Phoenix, Arizona 8501-4496. email: neuropub@ chw.edu. 